\title{
A New Beginning For Majalah Kedokteran Bandung (MKB) in 2019
}

\author{
Ahmad Faried, ${ }^{1}$ Reni Ghrahani ${ }^{2}$ \\ ${ }^{1}$ Department of Neurosurgery Faculty of Medicine Universitas Padjadjaran Bandung/Dr. Hasan Sadikin General \\ Hospital Bandung, West Java, Indonesia, ${ }^{2}$ Department of Child Health Faculty of Medicine \\ Universitas Padjadjaran Bandung/Dr. Hasan Sadikin General Hospital Bandung, West Java, Indonesia
}

\author{
"Ideally, an English manuscript should be written in English, not translated from Bahasa Indonesia" \\ -Diba Artsiyanti E. P. Basar
}

It's been a long journey since the first issue of Majalah Kedokteran Bandung (MKB) in 1967. It has gone through "unimaginable" obstacles and winding roads to serve a noble purpose of helping clinicians and scientists to spread their knowledge and disseminate their 'thought of wisdom' to the community. One of the main reasons that a good manuscript is rejected for publication is because of the language used to write the manuscript is inadequate for an academic manuscript. ${ }^{1}$ Since the beginning, MKB has received manuscripts both in Bahasa Indonesia and in English; and after 52 years of serving our fellow academicians and their community, MKB has decided to challenge itself to only publish manuscripts in English in early 2019 (Volume 51 No. 1 in March 2019) which marks a new beginning for this journal.

The world is changing rapidly and we might be familiar with the terminology of 'millennial generation'. Despite our lack of understanding on the meaning of this term, at least for some of us, it is already a part of our daily conversation. Millennial generation, which is known as "Generation Y", is a group of human beings born during the period of 1980 s to 1995 . This generation gets its name from the fact that it is the only generation that passes the second millennium since the theory of this generation was first introduced by Karl Mannheim in
1923. The generation after the millenials, born after 1995 to 2015, carries a different name "Generation Z", the sfuture generation. These generations are exposed to a totally different world of computerization, automation, artificial intelligence, and data reconciliation in a pursue to create a virtual copy of the physical world. Inevitably, the medical field, our field, needs to anticipate this era of disruption caused by the rapid advancement of technology. For this, we have to speak the same language to be able to understand each other, and English has been chosen by many as an official language to share knowledge.

These highlights the opportunities, challenges, and expectations that are currently faced and will be faced by MKB. After this new beginning, MKB will constantly make necessary changes to adapt to these rapid changes in the near future. May our efforts and hard work be supported by our stakeholders, who always hold a special place in our heart.

\section{Reference}

1. Faried A. Manuscript writing. Presented in Workshop of the $5^{\text {th }}$ Bandung International Biomolecular and Medicine Conference, $2^{\text {nd }}$ $4^{\text {th }}$ October 2018. Bandung: BIBMC; 2018. 